\title{
Discursos sobre homossexualidade e gênero na formação em pedagogia
}

\author{
Nilson Fernandes Dinis ${ }^{*}$ e Roberta Ferreira Cavalcanti ${ }^{* *}$
}

Resumo: Este artigo pretende discutir algumas concepçóes sobre o tema homossexualidade e gênero produzidas por estudantes de um curso de Pedagogia da Universidade Federal do Paraná. A análise quantitativa dos dados observados aponta inicialmente para uma melhor aceitação das diferenças sexuais e de gênero, porém uma análise mais detalhada aponta para uma assimilação do discurso politicamente correto, mas sem uma mudança significativa das concepçôes binaristas e excludentes sobre a produção das identidades sexuais e de gênero ou sobre a formação de novos modelos familiares no mundo contemporâneo. Destaca-se, por fim, a necessidade de maior espaço no currículo de formação em Pedagogia para discussão dos temas sexualidade e gênero.

Palavras-chave: homossexualidade; gênero; formação docente.

\section{Discourses about homosexuality and gender in pedagogy courses}

Abstract: This article intends to discuss some conceptions about the theme homosexuality and gender produced by undergraduating students of a pedagogy course in Federal University of Paraná. The quantitative analysis of the observed data points in the beginning to a better acceptance of sexual and gender differences, however a more detailed analysis points to an assimilation of politically correct discourse, but without a significative change in the binary and excluding conceptions about the production of sexual and gender identities or a about the formation of new models of family in the contemporary world. Finally it remarks the necessity of more space in the curriculum of pedagogy's formation to discuss themes such as sexuality and gender.

Key words: homosexuality; gender; teacher's formation.

As contribuiçôes trazidas pelos estudos da sexualidade de Michel Foucault possibilitaram a pesquisadores/pesquisadoras ${ }^{1}$ entender o conceito de sexuali-

\footnotetext{
* Professor adjunto do Departamento de Educação da Universidade Federal de São Carlos (UFSCar),SP.Brasil.ndinis@ufscar.br

* Licenciada em Pedagogia pela Universidade Federal do Paraná (UFPR). Brasil. robertaferreiracavanti@yahoo.com.br.

1. Em consonância com os estudos de gênero, entendemos a linguagem como espaço de produção de inclusōes e de exclusōes. Assim, procuraremos, ao longo deste texto, evitar o uso da forma
} 
dade não mais por um viés biológico ou naturalizante, mas por seu aspecto histórico-cultural. Os estudos de Foucault mostram que as verdades de cada tempo são construçôes históricas e, portanto, podem ser também desconstruídas. Assim também Foucault (2005) analisa a sexualidade como um dispositivo histórico de poder da modernidade, constituído por práticas discursivas e não discursivas, que produzem uma concepção do indivíduo como sujeito de uma sexualidade, ou seja, saberes e poderes que buscam normatizar, controlar e estabelecer "verdades" acerca do sujeito na sua relação com o corpo e com os prazeres. Foucault observa que mecanismos específicos de saber e poder centrados no sexo produziram discursos normativos sobre a sexualidade das mulheres, das crianças, dos casais e demarcaram o campo das perversôes sexuais, entre elas a homossexualidade.

Portanto, a própria constituição do sujeito homossexual é também uma constituição histórica. "Foi por volta de 1870 que os psiquiatras começaram a constituí-la (a homossexualidade) como objeto de análise médica: ponto de partida, certamente, de toda uma série de intervenções e de controles novos." (Foucault, 1992, p. 233). É dessa forma que se utiliza, pela primeira vez, o conceito de "homossexualidade" para referir-se a uma identidade sexual a ser vigiada e controlada. Seguindo a trajetória da perspectiva foucaultiana, Jonathan Katz (1996) ressalta como o próprio conceito de norma em torno do termo "heterossexualidade" também foi uma constituição histórica do fim do século XIX. O termo "heterossexual" teria sido criado por volta de 1892 , ou seja, depois do termo "homossexual", e designava, em um primeiro momento, o amor patológico e desmedido por pessoa do sexo oposto, só posteriormente adquirindo o sentido de norma e de referência para a sexualidade.

Já as discussôes sobre o conceito de gênero tornam-se presentes, principalmente, a partir dos trabalhos desenvolvidos pelos grupos feministas na década de setenta, questionando as representaçôes tradicionais que definem o que é ser mulher ou ser homem. A pesquisadora Dagmar E. Meyer ressalta que o conceito gênero representa "todas as formas de construção social, culturais e linguísticas implicadas com os processos que diferenciam homens de mulheres, incluindo aqueles processos que produzem os corpos, distinguindo-os e separando-os como corpos dotados de sexo, gênero e sexualidade" (Meyer, 2003, p. 16). Ainda, de acordo com a autora Guacira Louro, "não é propriamente o sexo ou não são exatamente as características sexuais que nos permitem dizer o que ou quem é masculino ou feminino, mas sim tudo aquilo que associamos

masculina como signo genérico referente a ambos os gêneros: feminino e masculino, nomeando, sempre que possível, as duas formas; tomando também o cuidado de alterná-las de forma a evitar uma precedência contínua do termo masculino que ocorre na construção usual da linguagem em estruturas como homem/mulher, masculino/feminino, professor/professora, aluno/aluna, etc. 
aos sexos, a forma como representamos determinadas características, comportamentos, valores e habilidades" (Louro, 1998, p. 88).

Por vivermos em uma sociedade que é pautada em concepções binárias e excludentes, a exemplo dos conceitos de heterossexual ou homossexual, homem ou mulher, também se dividiu o que é considerado próprio do gênero masculino e o que é próprio do gênero feminino, de modo que essas características pareçam naturais e imutáveis. Ainda, Marlene Strey (1998) afirma que a partir da concepção de dois gêneros diferentes passa a haver uma hierarquia de gênero, que descreve uma situação na qual o poder e o controle social sobre o trabalho, sobre os recursos e os produtos são associados à masculinidade, de forma que, no Brasil, por exemplo, produziu-se um sistema de organização social baseado na figura do "masculino", enquanto o provedor das riquezas, o comandante do sistema, o responsável pela igreja, etc. É claro que essa hierarquia de gênero se altera com todo o movimento da sociedade, mas os preconceitos da sociedade machista ainda se encontram fortemente marcados na formação social dos sujeitos.

A instituição escolar produz também essas categorias normatizantes de feminino e masculino, pois manteve durante muitos anos a educação sexista, com algumas escolas apenas para meninas e outras para meninos. Contudo, devemos ficar atentos a outras formas mais sutis de controle. Como aponta Monserrat Moreno (1999, p. 37), "o fato do ensino ter se tornado misto leva qualquer observador ingênuo a acreditar que a escola aboliu a discriminação sexista”. Mas se fizermos uma análise mais rigorosa, é possível afirmar que é justamente no ensino misto que aparecem mais claramente os processos de discriminação e de exclusão entre os gêneros, visto que agora estão juntas pessoas de diferentes categorias de gêneros que não podem apresentar o mesmo comportamento, a exemplo das brincadeiras consideradas socialmente corretas para meninas e para meninos; o uso discriminado das cores, como vermelho para o gênero feminino e azul para o masculino; as representações dos livros didáticos que costumam retratar e demarcar as atividades ligadas ao masculino e ao feminino; e mesmo o uso discriminado do banheiro. Também é o caso da linguagem que é feita, na maioria das vezes, no masculino plural, mesmo que haja mais alunas do que alunos. Aprender a expressar-se no masculino é, segundo Moreno, uma das primeiras experiências escolares dirigidas ao gênero feminino. Através dela a menina deve aprender

[...] sua identidade sexolingüística para imediatamente renunciar a ela. Permanecerá durante toda sua vida diante de uma ambiguiidade de expressão com a qual acabará se acostumando com o sentimento de que ocupa um lugar provisório no idioma, lugar que deverá ceder imediatamente quando aparecer no 
horizonte do discurso um indivíduo do sexo masculino, seja qual for a espécie a que ele pertença” (Moreno, 1999, p. 38).

Essa aprendizagem é tão duradoura que persiste, às vezes, mesmo no meio acadêmico. Como ressalta Louro (1999, p. 66), é “muito comum que uma profissional, já adulta, refira a si própria no masculino: "eu, como pesquisador...". Afinal, muitos comentariam, isso é "normal".

É também nessa perspectiva que Jurandir Freire Costa (1992) questiona o próprio conceito de homossexualidade, produzido pelo jargão psiquiátrico para designar uma categoria de perversão sexual. Propõe a substituição pelo termo "homoerotismo". Para o autor, longe de ser mero jogo de palavras, as categorias que criam as identidades sexuais não são universais, mas são também efeitos de linguagem. Resistir a termos patologizantes é também resistir à carga negativa com que a ciência e a cultura vêm sobrecarregando tais termos. Concordamos com o autor; no entanto, neste artigo utilizaremos o termo homossexualidade, por ser um termo mais conhecido e que serviu para nossa pesquisa sobre os discursos produzidos por estudantes de um curso de Pedagogia acerca do tema.

Todavia, o mundo contemporâneo tem se constituído também através de contestações e questionamentos em relação ao limite da norma. Conforme ressalta Louro (2004), vivemos um momento no qual as certezas escapam, os modelos mostram-se inúteis e as fórmulas, inoperantes, de maneira que se torna quase impossível estancar as novas questôes surgidas na modernidade. Não há como ignorar as "novas" práticas, os "novos" sujeitos e suas contestaçôes ao estabelecido. Por isso, a vocação normalizadora da Educação vê-se ameaçada. Conforme aponta Nilson Dinis (2006, p. 131), “essa dificuldade do espaço educacional em tratar de assuntos como a diversidade sexual talvez possa ser entendida pela predominância, nesta área, do conhecimento de proposiçôes cristalizadas e essencialistas para pensar a identidade”.

Esse processo de desnaturalização e desconstrução das categorias tradicionais das identidades sexuais e de gêneros deve-se, segundo Dinis (2006) e Louro (1999), à ação dos movimentos LGBT (lésbicas, gays, bissexuais e transgêneros) e do movimento feminista, que passaram a reinvindicar maior espaço para suas representaçôes no mundo contemporâneo.

Nesse contexto, a universidade tem sido chamada a sua responsabilidade diantes dessas discussóes, principalmente quando se refere a cursos de formação de professores/professoras, uma vez que na Educação há, de maneira geral, uma ausência desses estudos e ainda há uma demanda no espaço da escola acerca da discussão dessas questões. Assim, é fundamental que as/os profissionais da educação tenham um preparo, durante a graduação, para que possam trabalhar esses temas. 
Portanto, este artigo tem como objetivo discutir algumas das concepções sobre gênero e sexualidade produzidas por formandos/formandas de um curso de Pedagogia da Universidade Federal do Paraná (UFPR). Para isso, foi aplicado um total de 297 questionários, com questões sobre os temas gênero, sexualidade e homossexualidade às/aos estudantes do $4^{\circ}$ ano do curso de Pedagogia da UFPR, nos anos de 2005, 2006 e 2007. Nos questionários era dispensada a identificação da pessoa pesquisada, buscando-se atender as exigências éticas de uma pesquisa científica, mas também como forma de possibilitar maior liberdade de expressão.

Não houve grandes diferenças entre as turmas quanto aos anos em que foi realizada a pesquisa; assim, os dados serão analisados em sua totalidade, pois, de forma geral, mantiveram o mesmo padrão de respostas. Os resultados obtidos nesta pesquisa mostraram-se, em primeira análise, positivos quanto ao respeito às novas identidades sexuais e de gênero, uma vez que, quantitativamente, a maioria das pessoas pesquisadas apresentou respostas tipicamente consideradas como "politicamente corretas". A exemplo de ilustração, apresentamos alguns dos seguintes resultados: $89 \%$ dos/as discentes afirmaram que não mudariam sua conduta com um/a colega caso soubessem que ela/e é homossexual; $70 \%$ afirmaram que trabalhariam em uma escola com alunas/os homossexuais; $81 \%$ contratariam uma/um professora/professor homossexual e $56 \%$ disseram ser não preconceituosos/preconceituosas quanto à diversidade sexual.

Apesar de os números serem satisfatórios quanto ao repúdio às discriminações no ambiente escolar, é importante analisar os conteúdos das justificativas nessas questôes. Nesse sentido, um/a discente afirmou que não mudaria sua conduta com uma/um colega homossexual apesar de "não concordar com sua decisão de negar sua origem, ele é uma pessoa como eu, que merece respeito como eu.". Ou ainda quando se disseram não preconceituosas/preconceituosos, mas colocaram os seguintes poréns: "Não preconceituosa, respeito, mas não concordo com o homossexualismo", ou mesmo quando as justificativas religiosas serviram para reforçar os preconceitos: "Não preconceituosa, vocês que lerem esse questionário vão achar que sou preconceituosa. Mas não sou. Amo o homossexual, mas não amo o pecado dele. E já vi muitos homossexuais se libertarem disso. Deus fez o homem e a mulher e quero muito ajudar essas pessoas a descobrirem como é boa e perfeita a criação e vontade de Deus!”. Um outro exemplo presente é quando a mesma pessoa pesquisada se identificava como não preconceituosa, alegando que "ter uma opinião diferente não é preconceito", mas que, em resposta a outras questôes do questionário, posicionavase contra a adoção de crianças por casais homossexuais; contra a contratação de docentes homossexuais, ou mesmo justificava uma possível mudança de conduta em relação a um/a colega, caso ele/ela se identificasse como homossexual. 
De acordo com os conteúdos dessas justificativas, pode-se concluir que essas respostas mostradas pelos números como "politicamente corretas", provavelmente sejam, algumas vezes, apenas num plano teórico, e que efetivamente não condigam com a prática, uma vez que os conteúdos da justificativa, como nos casos citados acima, negam a opção marcada no questionário.

A construção social de nossos preconceitos dá-se muitas vezes, pela absoluta falta de novas informações no espaço educacional que problematizem nossas evidências, que desconstruam nossas certezas. Nesse sentido, a universidade também tem sua responsabilidade na construção dessas representações, pois $66 \%$ das/dos estudantes afirmaram que o tema "gênero" não foi trabalhado durante a graduação, todavia $82 \%$ deles/as consideram o tema importante. A maioria (76\%) entende que sexo e gênero são coisas diferentes, embora ainda $22 \%$ considerem como sendo coisas iguais. Isso talvez explique por que $28 \%$ dos/das estudantes acreditam que ser mulher ou ser homem é uma construção biológica, contrastando com apenas $11 \%$ que apontam ser uma construção cultural. A maioria (60\%) aponta ambas as alternativas, tentando conciliar as dimensões biológica e cultural; o que, embora seja um avanço frente a uma concepção estritamente biológica sobre as identidades de gênero, parece também indicar uma dificuldade em descolar as identidades de gênero de uma sobreposição sobre uma identidade biológica pré-formada. Ou seja, se reconhece a importância das variantes culturais, mas estas se sobrepõem, consolidando ou modificando uma identidade binária e excludente pautada na diferenciação biológica dos sexos.

Já em relação à sexualidade, os dados são um pouco mais positivos. Segundo $68 \%$ dos/as discentes, a questão da sexualidade foi discutida durante a graduação, principalmente nas disciplinas de Psicologia da Educação, Didática e Biologia Educacional. Entres os principais temas abordados, segundo os/ as estudantes, estão temas tradicionais, como a reprodução, DST/AIDS, gravidez, mas também, embora menos citados: preconceito e sexualidade na escola. Contudo, ainda que a sexualidade tenha sido objeto de discussóes, $81 \%$ dos/as alunos/as afirmaram não se sentir aptos/as para trabalhar com as questões que envolvam esse tema. Também, provavelmente, porque a questão da diversidade sexual, conforme a maioria $(57,5 \%)$ das/dos alunas/alunos, não foi um tema abordado, apesar de $85 \%$ delas/deles considerarem esse tema importante.

Dados como esses apontam para a necessidade de serem destinados mais momentos para as discussões sobre sexualidade, diversidade sexual e gênero dentro da universidade. Louro (2003) aponta para essa dificuldade de discutir esses temas dentro do ambiente escolar, uma vez que os/as educadores/educadoras são vulneráveis, sentem-se inseguros/inseguras e sem qualquer preparo para discutir os temas gênero e sexualidade ou para conviver com alunas/alu- 
nos de diferentes identidades sexuais e de gênero. Provavelmente sentem-se assim por um processo histórico de negação às diversidades sexuais e de gênero, principalmente quando o que está em pauta é um espaço escolar embasado por perspectivas essencialistas e normatizantes acerca das identidades.

Aparentemente essa dificuldade dos/das educadores/educadoras poderia ser justificada por uma falsa idéia de que a educação sexual é um tema novo nas escolas, contudo, o tema foi inserido legalmente no Brasil desde os anos 1920 e 1930, conforme afirma Helena Altmann, quando:

os problemas de "desvios sexuais" deixam de ser percebidos como crimes para serem concebidos como doença. A escola passa a ser tida como um espaço de intervenção preventiva da medicina higiênica, devendo cuidar da sexualidade de crianças e adolescentes a fim de produzir comportamentos normais. (Altmann, 2001, p. 575)

Dessa forma, a Educação Sexual, quando trabalhada, reforçava temas tradicionais normatizantes como a reprodução, a gravidez e as doenças sexualmente transmissíveis. Diferenças sexuais, como a homossexualidade, eram práticas que requeriam vigilância e cuidados especiais. Essa concepção de homossexual como um sujeito desviante e que, portanto, deve ser corrigido, também se mostrou algumas vezes em nossa pesquisa, quando, por exemplo, 27\% das/os estudantes afirmaram que tentariam convencer um/a filho/filha a mudar de orientação sexual caso essa/esse fosse homossexual. Entres as justificativas encontram-se frases como: "O homossexualismo não é saudável", "Não é natural", "Particularmente não aceitaria que meu filho fosse homossexual, devido a minha religião e isso seria contra as leis de Deus". Nesta última justificativa, outro dado importante a ser observado é a predominância das idéias religiosas na tentativa de justificar preconceitos, como também no seguinte discurso que mistura, ainda que contraditoriamente, argumentos religiosos com argumentos da biologia: "a homossexualidade é uma questão que envolve comportamento/educação familiar, e convicção religiosa. A Bíblia (o verdadeiro livro de sabedoria para o homem) diz que o ser humano não deve perverter o uso natural de sua biologia."

Em relação à influência da/do professora/professor homossexual sobre o/a aluno/aluna, a maioria (74\%) nega tal influência, às vezes através do argumento de que "a opção sexual sofre determinações de vários meios, não só dos professores”, mas às vezes também através da idéia determinista de uma préformatação das identidades sexuais que ocorreria na primeira infância. Porém, $24 \%$ dos/as estudantes acreditam que o/a professor/professora pode influenciar na orientação sexual do/da aluno/aluna. Provavelmente, nesses casos predo- 
mine ainda a concepção da homossexualidade como um vírus capaz de contagiar. Como afirma Deborah Britzman (1996, p. 79), há o medo de que "a mera menção da homossexualidade vá encorajar práticas homossexuais e vá fazer com que as/os jovens se juntem às comunidades gays e lésbicas. [...] o conhecimento e as pessoas são considerados perigosos, predatórios e contagiosos.".

A resistência à formação de novos modelos familiares também esteve bastante presente, sendo o item que mais dividiu os sujeitos pesquisados. Apesar de optarem entre ser favoráveis ou contra, essa também foi uma das questōes em que houve maior ausência de justificativas, bem expressa no estranhamento de uma das pessoas pesquisadas: "Não sei muito a respeito para explicar por que, mas prezo muito a tradicional 'família”. Ou ainda, "não sei ao certo... precisaria pensar melhor". Ou seja, parece haver um sentimento internalizado de inadequação, mas que não se consegue verbalizar de forma mais racionalizada.

De acordo com $48 \%$ das/dos estudantes, ou seja, quase a metade, os casais homossexuais não deveriam adotar crianças. Os argumentos, quando apresentados, giraram em torno da justificativa tradicional da necessidade de um pai biológico do gênero masculino e de uma mãe biológica do gênero feminino, que funcionariam como modelos da identidade sexual da criança. A isso se acrescenta uma argumentação bastante apressada e superficial, apropriada talvez dos discursos psicológicos: "Criança precisa de referencial masculino e feminino", "uma criança necessita conviver com pessoas (mãe e pai) em que os papéis e características dos gêneros são definidos”, "a maioria dos psicólogos já confirmou que causa danos imensos às crianças. Acredito firmemente na família (pai, mãe, filho) e na capacidade de educar para um mundo que tenha mais ética e moral". A última resposta é interessante por recorrer ao discurso psicológico, pois há da parte da pessoa pesquisada desconhecimento em relação à resolução do Conselho Federal de Psicologia no 1/99, de 23 de março de 1999, que estabelece normas éticas de atuação para psicólogas/os em relação à questão da orientação sexual, "considerando que a homossexualidade não constitui doença, nem distúrbio e nem perversão". Há também por parte da pessoa entrevistada a vinculação entre a idéia da preservação de um modelo familiar tradicional e o fortalecimento de valores como ética e moral.

Há ainda os/as que argumentam que vivemos em uma sociedade preconceituosa e que a criança sofreria muito preconceito advindo do fato de pertencer a uma família diferente da norma: "A própria criança sofreria com o preconceito. E na escola, quando questionada sobre sua família?”.

Porém, mesmo entre as/os que afirmaram concordar com a adoção (50\%), às vezes prevalecia o famoso argumento do "menos pior": "Sim, melhor ser 
adotado por eles do que ficar sem família”, "É melhor uma família com carinho do que um alojamento de orfanato", "Melhor do que ficar sem carinho de uma família”. Também, nesta questão, um/uma estudante, ao justificar sua resposta, evidenciou o fato de haver um discurso politicamente correto, mas que não condiz com a realidade, quando afirmou que: "provavelmente as pessoas se mostrem não preconceituosas dentro de uma histórica visão hipócrita das sociedades. Mas o sim, (o preconceito) na real, prevalece.".

Essa análise dos questionários confirma a hipótese de que as/os estudantes estão distantes de uma real aceitação e de que, às vezes, parecem apenas interiorizar posiçóes típicas de uma tolerância politicamente correta, devido, principalmente, ao conteúdo de suas justificativas. Louro (1998, p. 91) acredita que, mesmo no mundo contemporâneo, "apesar dessa pluralidade de arranjos, contudo, usualmente a escola afirma um único modelo e silencia, simplesmente, sobre as demais possibilidades. Tornadas invisíveis, essas outras famílias parecem menos "legítimas"; elas são postas à margem.". Essa negação pode ser explicada, entre outros motivos, provavelmente porque os/as professores/professoras não se consideram preparados/preparadas para a discussão do tema, também porque as próprias relaçôes sociais encarregam-se de retornar à norma, discriminando aquelas/aqueles que apresentam outro núcleo familiar.

Outra questão que corrobora a hipótese mencionada anteriormente é o fato de que a maioria (80\%) que afirmou que contrataria um/uma professor/professora homossexual condicionou sua aceitação a apenas se o/a mesmo/mesma “[...] apresentasse uma postura adequada", ou então, "desde que ele não coloque a sua opinião sobre o assunto". Exige-se da pessoa homossexual um comportamento quase assexual. Nessas justificativas, pode-se perceber um preconceito intrínseco ao fato de o/de a professor/professora ser homossexual, visto que ele/ela só seria contratado/contratada dependendo de sua postura, embora o mesmo tipo de posicionamento não seja colocado em relação a outros sujeitos heterossexuais.

Mas devemos ressaltar que o problema não é simplesmente aceitar ou tolerar as diferenças; o desafio é ultrapassar mesmo a idéia de tolerância por meio de políticas que questionem as próprias normas que produzem e categorizam as identidades sexuais e de gênero. Como aponta Louro:

É possível avançar, deste modo, de uma perspectiva de "contemplação, reconhecimento ou aceitação das diferenças" para outra, que permite examinar as formas através das quais as diferenças são produzidas e nomeadas. A questão deixa de ser, neste caso, a "identificaçãa" das diferenças de gênero ou de sexualidade, percebidas como marcas que preexistem nos corpos dos sujeitos e que servem para classificá-los, e passa a ser uma ques- 
tão de outra ordem: a indagação de como (e por que) determinadas características (físicas, psicológicas, sociais, etc) são tomadas como definidoras de diferenças. (Louro, 2003, p. 46).

Ou ainda, como destaca Dinis (2006, p. 134): “o debate não está na oposição simples de categorias como homem-mulher, masculino-feminino, heterossexual-homossexual, o debate está na fábrica de identidades exercida pela educação baseada em referenciais essencialistas e excludentes".

O desafio está em uma nova educação que questione os aspectos heteronormativos presentes na formação de nossas identidades sexuais e de gềnero, ajudando os/as educandos/educandas a descobrir o campo dos limites e das possibilidades impostas a cada pessoa quando se submete aos estereótipos que são atribuídos a uma identidade fixa sexual e de gênero. É importante aprender que não existe uma verdade única e universal sobre a sexualidade, o que exige revermos os mecanismos de saber-poder que constituem a própria sexualidade, muitas vezes através de perspectivas biologizantes e essencialistas. Compor uma nova ética na educação que nos possibilite reinventar novas relaçóes com nossos corpos, com nossos prazeres e com as outras pessoas. Ser afetado pelas inúmeras possibilidades de ser e existir no mundo, para além de verdades absolutas, tentando fazer da vida um eterno processo de criação da diferença: uma arte, ou, como nos provoca Foucault, ensaiar novas estéticas da existência.

\section{Referências bibliográficas}

ALTMANN, H. Orientação sexual nos parâmetros curriculares nacionais. Revista de Estudos Feministas, Florianópolis, v. 9 n. 2, p. 575-595, 2001.

BRITZMAN, D. O que é essa coisa chamada amor: identidade homossexual, educação $e$ currículo. Revista Educação è Realidade, Porto Alegre: v. 21, n.1, p. 71-96, 1996.

COSTA, J. F. A inocência e o vício: estudos sobre o homocrotismo. Rio de Janeiro: RelumeDumará, 1992.

DINIS, N. F. Educação, cidadania e as minorias sexuais e de gênero. In: SCHMIDT, M. A.; STOLTZ, T. (Org.). Educação, cidadania e inclusão social. Curitiba: Aos Quatro Ventos, 2006. p. 131-135.

FOUCAULT, M. História da sexualidade - In: A vontade de saber. 16. ed. Rio de Janeiro: Graal, 2005.

FOUCAULT, M. Microfisica do poder. Rio de Janeiro: Graal, 1992.

KATZ, J. N. A invenção da heterossexualidade. Rio de Janeiro: Ediouro, 1996.

LOURO, G. L. Um corpo estranho: ensaios sobre sexualidade e teoria queer. Belo Horizonte: Autêntica, 2004. 
LOURO, G. L. Currículo, gênero e sexualidade-O "normal", o "diferente" e o "excêntrico". In: LOURO, L.G.; NECKEL, F.J., GOELLNER V.S. (Orgs.). Corpo, gênero e sexualidade: um debate contemporâneo na educação. Petrópolis: Vozes, 2003. p. 41-52.

LOURO, G. L. Gênero sexualidade e educação: uma perspectiva pós-estruturalista. Petrópolis: Vozes, 1999.

LOURO, G. L. Sexualidade: liçóes da escola. In: MEYER, D. (Org.). Saúde e sexualidade na escola. Porto Alegre: Mediação, 1998. p. 85-109.

MEYER, E. D. Gênero e Educação: teoria e política. In: LOURO, L. G.; NECKEL, F. J.; GOELLNER, V.S. (Orgs.). Corpo, gênero e sexualidade: um debate contemporâneo na educação. Petrópolis: Vozes, 2003. p. 9-27.

MORENO M. Comose ensina a ser menina: o sexismo na escola. São Paulo: Moderna, 1999.

STREY, M. N. Gênero. In: CORRÊA JACQUES, M. G. et al. Psicologia social contemporânea. Petrópolis: Vozes, 1998. p. 181-193.

Recebido em maio de 2007 e aprovado em agosto de 2007. 